\title{
Development and Acquisition of Flavor and Food Preferences in Children: An Update Until 2010
}

\author{
Paloma Rohlfs Domínguez ${ }^{1,2}$ \\ ${ }^{1}$ Department of Psychology and Anthropology of the University of Extremadura, School of Nursing and \\ Ocuppational Therapy and Faculty of Teaching Training. Campus Universitario, s/n 10071, Cáceres (Spain) \\ ${ }^{2}$ Department of Experimental Psychology and Physiology of Behavior, University of Granada. Campus de \\ Cartuja s/n, 18071 Granada, Spain \\ Correspondence: Paloma Rohlfs Domínguez, Department of Psychology and Anthropology of the University of \\ Extremadura, School of Nursing and Ocuppational Therapy and Faculty of Teaching Training. Campus \\ Universitario, 10071, Cáceres (Spain).E-mail: palomaroh@ugr.es
}

Received: July 29, 2013 Accepted: November 15, 2013 Online Published: November 22, 2013

doi:10.5539/jfr.v3n1p1 URL: http://dx.doi.org/10.5539/jfr.v3n1p1

\begin{abstract}
The purpose of the present research is to identify the experience-related mechanisms which induce the establishment of children's flavor, food and drink acceptance and preferences. The development of children's preferences for flavors, foods and drinks is mediated by a variety of mechanisms, such as flavor transmission via amniotic fluid (AF) and neonatal feeding regimen (breastfeeding and formula milk-based feeding), mere repeated exposure, conditioned preferences for or aversions to gustatory stimuli based on subsequent postingestive consequences, parental strategies and food management of school meals. Operation of specific mechanisms is age-dependent, but they may have interacting effects. An essential feature of these mechanisms is exposure to flavors and foods, which requires prior selection of foods by adults and thereby guarantees cultural transmission of gastronomic habits. Promoting healthy patterns of food consumption by children, such as diets rich in vegetables, requires careful manipulation of these experience-related mechanisms. Flavor, food and drink preferences developed by young and older children appear to remain stable in later life stages, probably due to gustatory imprintings originated during prenatal gestation and childhood. However, the specific age ranges during which such gustatory imprinting may occur, remain, in most cases, unknown. In addition to this, there is a need for further research on specific aspects of the above-mentioned mechanisms to elucidate the development of food preferences in children. For example, the impact of breastfeeding history on later food and/or flavor preferences beyond infancy should be ascertained.
\end{abstract}

Keywords: flavor, exposure, children, food, preferences, learning

Abbreviations: AF: amniotic fluid; HCFs: hydrolyzed casein formulas; HPHFs: hydrolyzed protein hydrolysate formulas; SSS: sensory-specific satiety.

\section{Introduction}

Flavor is the most salient feature of foods and beverages for humans and its perception results from the interaction and integration of two kinds of chemical information, tastes and odorants (Small \& Prescott, 2005; Beauchamp \& Mennella, 2009). Additional sensory cues, such as temperature and texture, also contribute to food and beverage perception. There are five well-established basic tastes (sweet, bitter, sour, salt and umami) (Mojet, Christ-Hazelhof, \& Heidema, 2001). The quantity of odorants has been estimated to be approximately half a million (Kringelbach, 2007).

Flavor liking is the major determining factor of food preferences, and therefore food consumption in children (Burguess-Champoux, Marquart, Vickers, \& Reicks, 2006; Mennella \& Beauchamp, 2010). Consumption and hedonic evaluation of vegetables clearly illustrate this fact. Vegetables, such as spinach, broccoli and Brussels sprouts are typically rejected by children and are their least preferred food because of vegetables' unpleasant bitter taste (Wardle, Sanderson, Gibson, \& Rapoport, 2001; Rasmussen et al., 2006; Havermans, 2010). Instead of vegetables, young children often prefer snack foods that are rich in fats and sugars that can lead to childhood obesity (Skinner, Bounds, Carruth, Morris, \& Ziegler, 2004; Knai, Pomerleau, Lock, \& McKee, 2006; Warren, 
Parry, Lynch, \& Murphy, 2008), one of the most serious world-wide public health problems (Weker, 2006; WHO, 2009).

It is widely accepted that infants and young children are naturally predisposed to accept and prefer sweet and salty tastes over the bitter and sour basic tastes, which tend to be avoided (Mennella, Pepino, \& Reed, 2005; Mennella, \& Beauchamp, 2009). However, it is possible that early experiences with edibles, including vegetables, may induce and modify the establishment of stable flavor/food preference patterns (Menella \& Beauchamp, 2002; Skinner, Carruth, Bounds, \& Ziegler, 2002; Mennella, Kennedy, \& Beauchamp, 2006).

Human behavioral research has consistently demonstrated that the gustatory and olfactory functions, at least in terms of taste identification and merely liking or disliking, are already present in newborns (Faas, Spoltón, \& Molina, 2000; Mennella \& Beauchamp, 2005). Although gustatory and olfactory functions are already present at birth, their development continues postnatally (Bartoshuk \& Beauchamp, 1994; Schaal, 1999; Mennella et al., 2005; Schaal, 2005).

Human behavioral research has also consistently shown the existence of different postnatal sensitive periods throughout the development course of sensory functions (Knudsen, 2004; Johnson, 2005). Sensitive periods are restricted developmental stages, during which there is a biological display of an extreme neural sensitivity to the storage of experience-driven (gustatory and olfactory) information that is not present outside these developmental stages (Rohlfs Domínguez, 2011) which promotes normal (disease-free) development, and thereby contributes to individual survival (Hensch, 2004; Spolidoro, Sale, Berardi, \& Maffei, 2009). This neural property is reflected in behavior (Knudsen, 2004). Specifically, it induces imprinting effects -irreversible changes- in the individual's behavior (Bruer, 2001) and its underlying neural circuitry. Imprinting effects can be observed in subjects' reported preferences for sensory stimuli, such as flavors.

The present review is an attempt to identify different experience-related mechanisms that may shape preferences for flavors (tastes and odors), foods and/or drinks in infants and older children, as well as to identify possible sensitive periods for the development of such preferences. This knowledge is expected to contribute to the discovery of effective strategies for increasing children's healthy food intake patterns.

\section{Exposure-Related Mechanisms}

\subsection{Flavor Transmission Through the AF During Prenatal Development}

This first type of experience occurs during the prenatal stage of development, in utero. Here, fetuses are exposed to chemical compounds (tastes and odors) present in the mothers' diet that are transferred to AF within the placenta (Mennella \& Beauchamp, 1997a; Beauchamp \& Menella, 1998; Mennella \& Beauchamp, 1998a). These compounds come into contact with fetal chemical receptors as AF circulates through the oral-nasal passages. Throughout pregnancy, changes in the mother's diet are reflected in the chemical composition of AF (Mennella, Johnson, \& Beauchamp, 1995). There is also evidence indicating that fetuses show different swallowing patterns depending on the taste quality of specific substances injected into AF - sweet vs. Bitter-; fetuses appear to respond preferentially to sweet substances (De Snoo, 1937; Liley, 1972).

\subsubsection{Link Between Prenatal Experience With Flavors and Later Food Preference and Acceptance}

Prenatal chemical experience may induce the establishment of food and flavor preferences, as well as food-acceptance patterns that are maintained through weaning or even young adulthood. For example, Mennella, Coren, Jagnow, \& Beauchamp (2001) found that $5.7 \pm 0.2$ month-old infants whose mothers repeatedly drank carrot juice during pregnancy showed less negative facial expressions while eating a carrot-flavored cereal than did infants who had not been previously exposed to carrot juice in utero. An interview-based study (Mennella, Turnbull, Ziegler, \& Martínez, 2005) concluded that the kind of foods eaten by Mexican infants at weaning correlated with the type of foods their mothers ate during pregnancy. Crystal and Bernstein (1995) found that young adults whose mothers suffered moderate to severe vomiting during pregnancy showed greater preference for snack foods with the highest level of salt, in comparison to young adults whose mothers did not display such vomiting during gestation. A subsequent study (Crystal \& Bernstein, 1998) replicated these results in sixteen week-old infants. Specifically, infants whose mothers reported moderate to severe vomiting while pregnant exhibited less negative facial expressions in response to a liquid solution with high levels of salt, in comparison to infants whose mothers reported no or mild vomiting.

\subsubsection{Link Between Prenatal Experience With Flavors and Later Olfactory Preferences}

Olfactory preferences may also be learned in utero. For example, during tests conducted 16-30 minutes after birth, neonates cried significantly less when exposed to the odor of their mother's AF compared to infants exposed to their mothers' breast or those with no odor exposure (Varendi, Christensson, Porter, \& Winberg, 
1998). Moreover, within the first 2-4 postnatal days, infants responded preferentially to the odor of their own AF rather than the odor of formula milk, odorless distilled water, or unfamiliar AF (Marlier, Schaal, \& Soussignan 1998; Schaal \& Marlier, 1998). Schaal, Marlier, \& Soussignan (2000) demonstrated that in utero exposure to anise flavor resulting from the mother's consumption of anise-flavored sweets, led to a stable preference for anise odor at birth and postnatal day 4. Faas et al. (2000) found significantly higher rates of motor responsiveness to ethanol odor in 24- to 48 hour-old infants whose mothers reported frequent drinking during pregnancy, in comparison to infants whose mothers drank infrequently while pregnant. Mizumo and Ueda (2004) reported that exposure to the odor of mother's milk enhanced the efficiency of sucking activity by infants that were fed formula milk. Although these infants had no previous exposure to their mother's milk per se, these results may be explained by in utero exposure to odorants in the AF that were also present in the mother's milk.

\subsection{Flavor Transmission Through the Neonatal Milk-Based Feeding Regimen}

Once the baby is born, postnatal experiences with flavors and foods continue to induce acceptance of and preference for those chemical stimuli. Flavors from the mother's diet that are transmitted to her milk may be perceived by breastfeeding infants and such early exposure may result in the development of preferential responsiveness to food-related tastes and odors that remain observable throughout weaning. Mennella and Beauchamp (1991a) found that 3- to 4 month-old infants whose mothers ingested garlic spent more time attached to their mothers' breast and sucked more than did infants fed mothers' milk that was not garlic-flavored. Subsequent studies confirmed that infants' responsiveness to maternal breast milk varies as a function of the presence or absence of specific flavors associated with the mothers' diet, such as alcohol and vanilla (Mennella \& Beauchamp, 1991b; Mennella \& Beauchamp, 1994; Mennella \& Beauchamp, 1996; Mennella, 2001).

Specific flavor preferences resulting from formula-milk-based feeding have also been demonstrated (i.e., Mennella \& Beauchamp, 1996). Following a brief exposure to vanilla-flavored formula, three month old infants sucked significantly more when fed the vanilla-flavored formula rather than a control formula. Furthermore, during a second and longer feeding session, infants fed longer when the formula was vanilla-flavored.

\subsubsection{Food Acceptance Status at Weaning and Its Link to Flavor Transmission Through Breastfeeding}

Although the study conducted in Mexico (Mennella et al., 2005) found a relationship between the types of food eaten by infants at weaning and their mothers' diet during the lactation period, experimental research on this subject has yielded conflicting results. Indeed, Mennella and Beauchamp (1997b) found that infants showed higher rates of consumption of a carrot-flavored cereal at weaning (175.5 \pm 6.8 days) when the cereal was prepared with their mother's milk rather than water. The authors of the study attribute this effect to prior exposure to the carrot flavor (via the mother's diet) during the lactation period. Infants in this study had been fed cereal for a short period of time; an average of $12.9 \pm 1.5$ days. In a subsequent study (Mennella \& Beauchamp, 1999), however, $3.4 \pm 1.0$ month-old infants who had been fed cereal for a somewhat longer period of time (mean $=21.3 \pm 2.0$ days) consumed less carrot-flavored cereal than cereal prepared with water and spent less time feeding if they had been exposed to the flavor of carrots in their mother's milk during the lactation period, in comparison to control infants. The authors of the study attribute this effect to sensory specific satiation (SSS) (Mennella \& Beauchamp, 1999), the mechanism through which a recent repeated exposure to a given flavor or food leads to decreased consumption of that food (Rolls, Rowe, \& Rolls, 1982). A subsequent study (Mennella et al., 2001) showed that $5.7 \pm 0.2$ month-old infants whose mothers drank carrot juice during the first two months of lactation preferred cereal prepared with carrot juice rather than plain cereal at $4 \pm 0.5$ weeks of weaning, and ate more of the flavored cereal than did infants with no prior carrot exposure. The same pre-exposure effect was found in breastfed infants aged from 4 to 8 months whose mothers had high rates of fruit consumption. These previously breast-fed infants, who had been eating solid food for $6.7 \pm 1.6$ weeks when tested, ate more peaches than did infants who were previously fed artificial formula (Forestell \& Mennella, 2007).

\subsubsection{Food Acceptance at Weaning and Its Link to Flavor Transmission Through Formula Milk Feeding During} Infancy

Effects of gustatory imprinting through exposure to artificial milk have also been observed at weaning. In a recent study (Mennella, Forestell, Morgan, \& Beauchamp, 2009), infants were fed HCFs -which taste bitter, sour and savory and have an unpleasant odor (Mennella et al., 2009)- during the first three months of life. When tested after weaning (at 4-9 months of age) these infants ate more cereals characterized by these same tastes and odors than did infants fed bovine milk-based formulas, or breast milk. Mennella, Griffin and Beauchamp (2004) found that infants who were fed a specific HCF (Nutramigen) for a period of seven months more readily accepted Alimentum (another HCF, similar to Nutramigen), than did control infants who had been fed a milk-based formula (Enfamil) for the same period. In a subsequent study (Mennella \& Beauchamp, 2005), 
infants aged from 5 to 11 months preferred the HCF that they were being fed at the test moment, either Nutramigen or Alimentum, whereas infants that were being fed milk-based formulas rejected both HCFs.

2.2.3 Link Between Food Preference and Acceptance in Early Childhood and Beyond and Flavor Transmission Through Neonatal Milk-Based Feeding

Imprinting effects associated with prior experience with flavors during formula feeding may still be evident beyond infancy. For example, Mennella and Beauchamp (2002) reported that children who had been fed soy-based formulas -which taste sweet, sour and bitter and have a strong hay odor- preferred bitter-flavored juice, while children fed HCFs preferred sour-flavored apple juice significantly more than children who were fed milk formulas. Furthermore, both of these groups were more likely to prefer broccoli than the group fed milk-based formulas, as reported by their mothers. These results were replicated in another study, in which age appeared to determine the degree of flavor preference (Liem \& Mennella, 2002). Specifically, four to five year-old children who had been fed HCFs during the lactation period preferred apple juice with higher levels of citric acid than six to seven year-old counterparts who also were fed HCFs. Similarly, Haller, Rummel, Henneberg, Pollmer, and Köster (1999) found a positive correlation between experience with vanilla-flavored formula milk in early life stages and the preference for this flavor by subjects aged 12 to 59 years. Further research is needed to determine whether breastfeeding can also induce such long-lasting effects on flavor preferences.

Based upon these data, we can conclude that the effects of gustatory imprinting acquired by breast- and formula-feeding infants during the lactation period continue through early childhood. Although pre-exposure effects have been demonstrated in both breast- and bottle-fed infants, these two feeding methods differ considerably in the strength with which they facilitate infants' acceptance of new solid foods at weaning. The breast-feeding regimen induces this acceptance more efficiently than bottle- feeding, as demonstrated by Sullivan and Birch (1994). The authors of this study attribute this result to the fact that breast milk is rich in a variety of flavors, while the flavor of formula milk is quite consistent across feedings.

\subsubsection{Olfactory Imprinting During the Lactation Period}

Olfactory preferences may be learned during early stages of postnatal development that might constitute sensitive periods for such learning. In this sense, one of the first odors that neonates learn is the natural scent of their mothers' breasts (Macfarlane, 1975; Russell, 1976; Varendi, Porter, \& Winberg, 1994; Sullivan \& Toubas, 1998). Neonates are able to acquire a preference for this odor via repeated breastfeeding experience within the three to four postnatal days. For example, Varendi and Porter (2001) reported that full-term babies who had been breast fed on 6-24 occasions crawled preferentially towards a breast pad that their mother wore prior to the test, rather than towards a clean control pad. Breastfed neonates' preference for an odor (i.e., chamomile) that had been previously applied to their mothers' breasts before nursing has also been observed (Delauney-El Allam, Marlier, \& Schaal, 2006). Infants exposed to camomile in this manner spent significantly more time oriented towards the source of camomile odor than to the source of control odorants (Delauney-El Allam et al., 2006).

Olfactory preferences for odors that do not emerge from the body can also develop as a function of early experiences. For example, Balogh and Porter (1986) observed that female infants who had been previously exposed to either a cherry or ginger scent spent significantly more time oriented toward the familiar odor than to a non-familiar odor. A subsequent study (Mennella \& Beauchamp, 1998b) demonstrated that duration of parental alcohol consumption over their lifetime, as well as mother's frequency of consumption of vanilla-flavor during lactation, correlated significantly with infants' $(7.5 \pm 0.2$ month-old $)$ responses to toys treated with those same scents.

In addition to these studies, another report indicate that even a short exposure to odorants may induce such early olfactory imprinting. For example, a sample of $11.20 \pm 2.15$ minute-old full-term neonates delivered via elective cesarean section, and whose mothers suffered contractions prior to delivery, were exposed for $30.5 \pm 1.8$ minutes to either the odor of cherry or passion fruit (Varendi, Porter, \& Winberg, 2002). When tested at a mean age of 80 hours, these neonates oriented preferentially towards the source of the familiar exposure odor compared to a control odor. In contrast, neonates whose mothers did not suffer labor contractions responded indiscriminately to the exposure vs. control odors.

We can, therefore, conclude that the contact with flavors (tastes and odors) during three successive stages of early development results in modifications in the expression of flavor, food and drink preferences that may be observable in later life stages. These developmental stages are: the prenatal period (fetal experience), the postnatal milk-based feeding period and early childhood (at weaning). 


\subsection{Effects of Repeated Exposure to Foods at Weaning and Young Childhood on Food Acceptance and Preference}

Empirical research has demonstrated that repeated exposure to novel foods, including vegetables, during the transition from milk-based feeding to solid foods at weaning, increases acceptance of these foods (Sullivan \& Birch, 1994; Birch, Gunder, \& Grimm-Thomas, 1998; Gerrish \& Mennella, 2001; Maier, Chabanet, Schaal, Issanchou, \& Leathwood, 2007; Maier, Chabanet, Schaal, Leathwood, \& Issanchou, 2008; Mennella, Nicklaus, Jagolino, \& Yourshaw, 2008). Furthermore, in the case of infants who were breast fed, mere repeated exposure to new foods at weaning increased food acceptance significantly more than in the case of infants who had been formula fed (Sullivan \& Birch, 1994).

Mere repeated exposure to a variety of flavors at weaning has been observed to increase acceptance of new foods (puréed carrots and puréed chicken) significantly more than mere repeated exposure to just one flavor (Gerrish \& Mennella, 2001). Moreover, repeated exposure to a variety of new flavors, including flavors of green vegetables, at the start of weaning, in combination with a previous history of breast-feeding, increased significantly acceptance of new foods, including fish and meat, in comparison to control conditions, with this effect lasting at least two months (Maier et al., 2008).

Repeated mere exposure (at least 8 exposures) to unfamiliar foods, including vegetables, tends to increase young children's liking and preference for those novel foods (Torrance, 1958; Rozin, 1979; Birch \& Marlin, 1982; Pliner, 1982; Sullivan \& Birch, 1990; Kern, McPhee, Fisher, Johnson, \& Birch, 1993; Gerrish \& Mennella, 2001; Wardle, Herrera, Cooke, \& Gibson, 2003; Cooke, 2007; Gibson \& Brunstrom, 2007; Williams, Paul, Pizzo, \& Riegel, 2008).

On the other hand, Mennella and García (2000) reported that 3.8 to 6 year-old children whose mothers, fathers or both parents drank beer, liked the odor of beer more than children whose parents did not drink. However, among the children whose mothers, fathers or both parents drank beer, preferences for beer odor were significantly related to parents' specific emotional state when they consumed alcohol. That is, children whose parents drank as a means to cope with negative mental or emotional states disliked significantly more the odor of beer than did children whose caregivers did not drink in the same negative context. This pattern of results was replicated in a subsequent study (Forestell \& Mennella, 2005) in 3 to 8 year-old children regarding cigarette odor.

Therefore, repeated exposure to flavors, foods and drinks at weaning and during young childhood improves food acceptance and preference.

\subsection{Young Children's Conditioned Preferences for or Aversions to Gustatory Stimuli Based on Subsequent Postingestive Consequences as Well as Flavor}

In a broad sense, this process involves ingestion of an edible substance followed by a specific physical sensation, the postingestive consequence, that is the determining factor of either preference for or aversion to that substance. The two most well-known postingestive consequences that have been shown to condition young children's preferences for and aversions to flavors, foods or drinks are the sensation of satiety, derived from the nutritive effects of ingested energy, a positive reinforce for those preferences (Birch, 1992; Birch, 1999), and nausea and emesis, negative reinforces (Rozin \& Fallon, 1987; Birch, 1999), respectively. When acquisition of flavor or food preferences is based on the pleasant nutritive effects of ingested energy, then the terms flavor-nutrient learning or flavor-nutrient conditioning are used to designate that process (Appleton, Gentry, \& Sheperd, 2006; Mobini, Chambers \& Yeomans, 2007; Zeinstra, Koelen, Kok, \& De Graaf, 2009). In other cases, neutral flavors or foods have been contingently paired with an already liked or disliked flavor/food, thus leading to increases or decreases in liking for flavors, respectively. The process of acquiring food aversions based on negative postingestive reactions is designated as taste aversion learning.

\subsubsection{Flavor-Nutrient Learning as a Basis for Food Preferences in Children}

Two well-controlled studies have shown that young children prefer high energy-density novel flavored edible substances - over low-energy-density flavors - following a series of repeated pairings of those flavored edible substance with the energy source (carbohydrates or fat) (Birch, McPhee, Steinberg, \& Sullivan, 1990) and (Johnson, McPhee, \& Birch, 1991). These studies also indicate that young children are able to compensate their caloric intake at a meal, depending on the calories previously ingested. That is, they eat more following consumption of a meal with a low, rather than high, fat or carbohydrate content, thus confirming young children's responsiveness to caloric density (Birch et al., 1990; Johnson et al., 1991). These results have been attributed to the presence of positive postingestive consequences of calorie intake, which, along with learned safety, may contribute to reduced neophobia (Birch et al., 1990; Johnson et al., 1991). It is important to stress here that young children's acquisition of gustatory preferences in the context of this conditioning paradigm is 
presumably facilitated by repeated exposure to gustatory stimuli that, unlike the mechanism of mere exposure, is linked to the specific consequence of the positive nutritive effects of ingested energy. To further assess this hypothesis, both a mere exposure group and a conditioning group were compared in a study by Kern et al., (1993). Moreover, the children assigned to this last group were exposed to the conditioning intervention after an overnight fast, to investigate whether preferences for flavors associated with caloric substances are influenced by participants' hunger level. The authors reasoned that if preferences for flavors are conditioned based on the positive nutritive effects of ingested energy, then the satiety/hunger state of participants should influence the expression of these preferences (Kern et al., 1993). The results suggest that young children learn to prefer flavors paired with the postingestive consequences of ingested energy from dietary fat, since only the preference for the high-fat-content edible substance increased after conditioning (Kern et al., 1993). Furthermore, the expression of the flavor preferences acquired during the conditioning intervention varied as a function of the young children's satiety/hunger state; preference for the high-energy-dense edible was more marked in the hungry than in the satiated state. Mere exposure did not lead to a differentiated preference for flavors as a function of the fat content of the edible substance, or the satiety/hunger state (Kern et al., 1993). Young children's flavor-nutrient learning has been reported with both familiar (puddings) (Birch \& Deysher, 1985; Birch \& Deysher, 1986) and novel foods, and with innately rejected (e.g. sour) fruit juices (Capaldi \& Privitera, 2008). In older children (8-10-years-old), flavor-nutrient learning has been shown to occur with the innately liked sweet taste but not with the innately aversive sour taste (Liem \& De Graaf, 2004). Flavor-nutrient conditioning has been suggested to be also potentially effective in increasing young children's liking for vegetables (Havermans \& Jansen, 2007). Indeed, Gibson and Wardle (2003) found that mothers' ratings of their young children's preferences for different common foods, including vegetables, correlated with the energy-density of these foods.

\subsubsection{Young Children's Conditioned Preferences Based on Flavor-Flavor Learning}

This mechanism facilitates a conditioned increased or decreased liking for originally neutral flavors or foods that have been contingently paired with a previously liked or disliked flavor/food, respectively (Baeyens, Elen, Van den Bergh, \& Crombez, 1990; Birch, 1999). Occurrence of this effect in children has been examined mostly in regard to vegetable consumption. For example, Havermans and Jansen (2007) found that children of an average age of 5.2 years showed a greater preference for a vegetable-flavored solution following repeated exposure with added dextrose, in comparison to children who had been exposed to a non-sweetened vegetable-flavored solution. This result has been replicated in older children's (8-10-year-old) in an unpublished study by Havermans and Jansen (see Havermans, 2010).

\subsubsection{Children's Acquisition of Taste Aversions}

Evidence of learned taste aversions resulting from the pairings of nausea or emesis with food is provided by observations of pediatric cancer patients undergoing drug treatments (chemotherapy). While some drug treatments have toxic effects on the gastrointestinal tract and are associated with moderate- to high levels of nausea, others do not produce such toxicity (Goodman \& Gilman, 1975). Bernstein (1978) reported that 2-16 year old patients with neoplastic disease developed a taste aversion for a novel ice cream that was consumed before toxic chemotherapy. No such aversion occurred in patients who were being treated with non-toxic chemotherapy or patients who did not consume the ice cream but experienced gastrointestinal tract toxicity. One pairing of ice cream with drug induced gastrointestinal tract toxicity in those patients. They developed a taste aversion for the ice cream that endured for at least 2 weeks. A subsequent study (Bernstein, Webster, \& Bernstein, 1982) demonstrated that learned taste aversions can be developed by pediatric cancer patients for familiar as well as novel foods. Indeed, 2- 18-year-old cancer patients reported reduced liking/preferences for foods that they frequently consumed in their usual diet, following pairing of those foods with gastrointestinal tract toxic chemotherapy. Such aversions were significantly less apparent when patients were also exposed to a novel ice cream before the beginning of the treatment, indicating that the introduction of novel foods prevents or attenuates acquisition of aversions for familiar foodstuff (Bernstein et al., 1982). The authors of these studies conclude that the anorexia and weight loss typically developed by pediatric cancer patients (Van Eys, 1979) may be due, at least partially, to such learned taste aversions. As described above, the unpleasant post-ingestive consequences -nausea or emesis- in the taste aversion learning studies did not result from the food, per se, but from a negative event that was introduced after the food was eaten. It is reasonable to assume that taste aversion learning would likewise occur if the unpleasant postingestive consequence derived directly from the edible substance. Therefore, associating a food with any event or situation that has potentially negative consequences may contribute to the development of taste aversion learning in children. This may be especially relevant when considering childhood anxiety and eating disorders. For example, there is evidence of co-occurrence of feeding problems, such as food refusal and eating disorders, with anxiety-depressive symptoms and anxiety disorders in 
children (Timini, Douglas, \& Tsiftsopoulou, 1997; Chatoor \& Ganiban, 2003; McDermott, Forbes, Harris, McCormack, \& Gibbon, 2006). Furthermore, children may experience nausea during stressful situations, which triggers high levels of anxiety (Pynoos, Steinberg, \& Piacenini, 1999).

These three processes are forms of conditioning because in either case the flavor or the food is paired with a physical sensation, either satiety, in the case of the former process, or nausea/emesis, in the case of the latter process (Havermans, 2010) or even another flavor, in the case of the second process. In view of these studies, we main affirm that conditioning is another mechanism that induces the establishment of children's flavor, food and drink acceptance and preferences.

\subsection{Parental Influence on Children's Exposure to Flavors and Foods}

Parents' influence on the formation of their own children's patterns of food intake and food preferences is high. Since parents decide which kind of foods shall be purchased and served in the household, they thereby determine what their children consume and thus what they are exposed to (Wardle, 1995; Scaglioni, Salvioni, \& Galimberti, 2008). In addition to this, other mechanisms through which parents influence the development of children's dietary habits have been identified, and are discussed next.

\subsubsection{Parents' Transmission of Their Own Food Consumption Patterns to Their Children via Direct Modeling}

Hood et al., (2000) observed that 3-5-year-old children whose parents reported a high degree of lability in eating behavior and weight, coupled with dietary restraint, showed high rates of body fat, that may be attributed to parental modeling. Influence of parental adult modeling has also been shown to operate in older children. Moreover, Brown and Ogden (2004) found that 9- to 13-year-olds and their parents share identical patterns of snack food consumption. Peer modeling also plays a role in young and older children's food intake (Romero, Epstein, \& Salvy, 2009). However, the influence of parental adult modeling on children's eating habits may not be identical since adults are more often perceived as authority figure (Batsell, Brown, Ansfield, \& Paschall, 2002).

\subsubsection{Parental Child-Feeding Strategies}

Certain parental strategies commonly used in daily life to regulate children's eating behavior exert an important influence on their food choices and preferences (Birch \& Davison, 2001; Scaglioni et al., 2008). Parental influence on children's eating behavior can be positive or negative, depending on the specific strategy that is used. Forcing or restricting eating of certain foods, rewarding food intake or promoting children's pro-social behaviors with food rewards, even when applied with the best intentions, may not have the desired effect and the results might even be opposite to what the parents intend (Birch, Marlin, \& Rotter, 1984; Fischer \& Birch, 1999; Reimer et al., 2003; Brown \& Odgen, 2004; Galloway, Fiorito, Francis, \& Birch, 2006). Thus, pressuring young children to eat vegetables may result in a decreased preference for those dietary items (Fisher, Mitchell, Smiciklas-Wright, \& Birch, 2002; Wardle, Carnell, \& Cooke, 2005). Restricting children's access to foods, such as snack foods, in turn, increases their intake and desire for those items (Fisher \& Birch, 1999), while permitting children to eat as much as they want does not increase their preference for the relevant foods (i.e., vegetables) (Wind et al., 2006; Brug, Tak, Te Velde, Bere, \& De Bourdeaudhuij, 2008).

On the other hand, enhanced availability and accessibility of particular foods have been shown to correlate positively with intake of that food by children (Brug et al., 2008). Overt parental control that clearly communicates how much the child should eat, as well as covert control strategies (i.e., not purchasing undesirable foods), have been related to greater consumption of fruits and vegetables in 4- to 7-year old children (Brown, Ogden, Vögele, \& Gibson, 2008).

Indeed, parents may influence the formation of their own children's patterns of food intake and food preferences. Ideally, parents should become familiar with the wide range of child-feeding strategies, and then select the most appropriate strategy according to the targeted food.

\subsection{Children's Exposure to Flavors and Foods at School}

Several countries, such as Spain, United Kingdom, Ireland, Argentina, Sweden, United States of America, etc. provide children with foods at the school dining rooms (Engström \& Carlsson-Kanyama, 2004; Sosa \& Hough, 2006; Moore, Murphy, Tapper \& Moore, 2010). Therefore, the school is an environment that provides many children with edibles worldwide and thus may shape child food preferences and eating habits, this statement having received empirical support (i.e. Briefel, Crepinsek, Canili, Wilson, \& Gleason, 2009; Lytle, 2009).

Indeed, exposure to foods at school dining halls may impact children's eating behavior and dietary preferences in two ways. On the one hand, the simple provision of foods during the schools' routine mealtimes, without 
implementation of special intervention programs, may increase children's preferences for those foods. Indeed, over a three year period, 8-10 year-old children whose school diet was rich in fruits and vegetables showed increased consumption and preference for those edibles (Baxter \& Thompson, 2002). Another study (Sepp, Abrahamsson, Junberger, \& Risvik, 2002) found that 4-year-old children ate vegetables at least once a day during weekdays in the school, while at home the same children ate vegetables less than once a day. On the other hand, related studies reveal positive effects of school-based intervention programs on the development of preferences for healthy foods in children. The majority of these school-based interventions have focused on fruits and vegetables as the targeted foods. These school-based interventions can be broadly classified into three different types according to their focus.

\subsubsection{School-Based Interventions Focused on Nutrition Knowledge}

Nutrition education programs mainly involve teaching children healthy nutritional habits in the classrooms, and organizing cooking workshops where they can observe and even practice healthy culinary skills. These programs are usually combined with other activities that are not strictly aimed to providing nutrition information. For example, over an 8 month period, the integration of healthy nutrition-related lessons in the classroom and vegetable gardening activities yielded an increase in the young children's willingness to taste vegetables, such as spinach, broccoli and carrots, although their preference for these vegetables did not change (Morris, Neustadter, \& Zidenberg-Cherr, 2001). Morris's et al's study was subsequently replicated with older children (Morris \& Zidenberg-Cherr, 2002). Over a one-year period, healthy nutrition-related lessons in the classroom combined with vegetable gardening activities, as well as the nutrition-related lessons alone, significantly improved children's preferences for carrots and broccoli compared to a control condition with no intervention. Furthermore, children in the first condition preferred peas and zucchini significantly more than children of the second and third condition. These effects were still observed six months later. In a related study, six to twelve-year-old children who experienced a combination of fruit and vegetable taste tests, preparation of fruits and vegetables, and gardening activities, showed increased preferences for vegetables, but not for fruits (Heim, Stang, \& Ireland, 2009). A final education program that was focused primarily on the five senses, included lessons on sense-related vocabulary, gustatory and olfactory experience, information regarding local gastronomic specialties and a cooking workshop over a period of 4-6 months (Reverdy, Schlich, Köster, Ginon, \& Lange, 2010). Children (8-10 years old) who participated in this program displayed an increased preference for two of three food stimuli -potatoes and apple compotes- that was observable 10 months later, but not immediately after the intervention.

\subsubsection{School-Based Interventions Focused on Meals}

This type of programs involves modifications in the schools' meals, such as addition of fruits and/or vegetables, or modifications in the conditions under which children have access to meals in the school. Manipulation of these independent variables and measurement of changes in children's preferences for the target fruits and/or vegetables as the dependent variable are then performed. In a study by Hendy, Williams and Camise (2005), children (mean age $=8.0$ years) were exposed to fruits and vegetables for 18 consecutive meals under conditions of token reinforcement, food choice and peer modeling. Two weeks after the end of the experimental treatment, the children subjected to this multi-component school-based intervention preferred fruits and vegetables significantly more than did children in an untreated control group, but no differences between the groups were found seven months later. An additional study included changes in the content of school meals, gardening activities, cooking classes and nutrition lessons (Wang et al., 2010). Eight- 10-year-old children who participated in this program for 2 years showed a significantly greater increase in their preferences for fruit and green vegetables compared to children with only one year of exposure.

Therefore, the school environment shapes children's food preferences and the resulted eating habits.

\section{Additional Evidence on Prediction of Later Dietary Preferences/Habits Based on the Preferences Developed During Young Childhood}

Several authors have found that specific food preferences developed during young childhood through the different experience-related mechanisms explained in previous sections of the present paper predict dietary preferences in later childhood and even young adulthood. For example, food preferences of 8-year-old children were related to their preferences at 2- 4 years (Skinner et al., 2002). Similarly, Nicklaus, Boggio, Chabanet and Issanchou (2004) found the same relationship between the status of food preferences of young children (aged from two to three years) and the preferences of the same participants when $12-22$ years old. Another study (Skinner, Carruth, Bounds, Ziegler, \& Reidy, 2002) concluded that food-related experiences by children in the first 2 years of life predicted their diet variety at 6,7 and 8 years. Other aspects of young children's food-related behavior has also been reported to track into young adulthood. In fact, the preferred degree of food variety of 
22-year-old adults was found to be related to the degree to which those individuals sought food variety when 2 and 3 old (Nicklaus, Boggio, Chabanet, \& Issanchou, 2005). Therefore, one can predict later dietary preferences/habits based on the preferences developed during young childhood. Which age ranges of childhood constitute sensitive periods for food acceptance/preference development is a question that requires further research.

\section{Final Remarks and Future Research}

The global aim of the present review has been to enhance our knowledge of the origin of developing individuals' flavor acceptance and preferences, and thereby help to generate effective strategies for increasing children's healthy food intake patterns. In this sense, the present review indicates that several experience-related mechanisms impact children's food preferences and choices. Although human beings naturally accept and reject sweet or salty as well as sour and bitter tastes, respectively, prenatal and postnatal contact with different flavors shape the degree to which those innate predispositions are expressed. Moreover, certain experience-related mechanisms operate during three successive stages of early development: the prenatal period (fetal experience), the postnatal milk-based feeding period and early childhood (at weaning). Contact with gustatory and olfactory cues (flavors) via these mechanisms takes place across development and results in modifications in the expression of flavor, food and drink preferences that may be observable in later life stages. These experience-related mechanisms may ensure cultural transmission of gastronomic preferences across generations since the foods and flavors to which children are exposed are mostly decided by adults. Children, for their part, assimilate this gastronomic culture, similarly to other cultural aspects, and when they become adults, they may transmit their learned food preferences and nutritional habits to their own children. Thus, culinary habits and preferences may remain stable for centuries. Once those experience-related mechanisms are known, adults may use them in order to improve children's exposure to healthy foods, such as vegetables, at home and in the schools.

On the other hand, the present review has also identified the following relevant issues/questions that are in need of additional research: 1 . The impact of the length of the time interval between exposure to foods, and the test moment, on the emergence of increased acceptance, consumption and preference for those foods, on the one hand, and SSS, on the other hand, needs elucidation. 2. The impact of breastfeeding history on later food and/or flavor preferences beyond infancy should be ascertained. 3. It would also be interesting to test the effectiveness of repeated mere exposure on infants' and young children's acceptance of and preference for fluids, as well as the effectiveness of flavor-nutrient learning with solid foods in young and older children. 4. Another open research question is whether taste aversión learning might contribute to eating disorders in childhood. 5. It would be interesting to ascertain whether young and older children's preferences for foods other than vegetables, also increase through flavor-flavor learning. 6. Flavor-related olfactory conditioning in children has not yet been studied. 7. The impact of parental /adult modeling on young and older children's food preferences and associated long-lasting effects is also a mystery. 8. Future school-based intervention programs should assess the effects of taste-related experiences with the target foods on the modification of young children's food preferences.

Regarding the existence of sensitive periods for the development of flavor, food and/or drink preferences, it is important to say that, compared with the visual and auditory domains, potential sensitive periods of neural responsiveness to gustatory and olfactory stimuli, have been less studied. Evidence described in previous sections indicates that very early experiences with flavors and foods induce a gustatory imprinting that is displayed in preferences for those same stimuli in later stages of life. Nonetheless, the specific age or ages during which such gustatory imprinting may occur, remain, in most cases, unknown, and therefore, this enigma needs additional research. To the best of our knowledge, the only study that has addressed this issue was reported recently by Mennella, Lukasewycz, Castor and Beauchamp (2011). These authors found that learned acceptance of high sour- and bitter-tasting HPHFs by human infants was restricted to $1.5-3.5 \mathrm{mo}$. of age.

Finally, we hope that this review has contributed to a better understanding of the role of early experiences with flavors, foods and drinks in the development and shaping of gustatory and olfactory preferences, and that it may inspire further research and clinical strategies focused on increasing children's healthy food intake patterns.

\section{Conflict of interest}

There are no conflict of interest to declare.

\section{Acknowledgements}

This work has been partially supported by the pre-doctoral fellowship of Junta de Andalucía and the project HUM-02763 of the University of Granada (Spain). I would like to thank Dr. Richard H. Porter for his effort 
invested in reviewing this paper, thus making interesting suggestions on the text and refining the English language of the text.

\section{References}

Appleton, K. M., Gentry, R. C., \& Sheperd, R. (2006). Evidence of a role for conditioning in the development of liking for flavours in humans in everyday life. Physiology and Behavior, 87(3), 478-486. http://dx.doi.org/10.1016/j.physbeh.2005.11.017

Baeyens, F., Eelen, P., Van den Bergh, O., \& Crombez, G. (1990). Flavor-flavor and color-flavor conditioning in humans. Learning and Motivation, 21(4), 434-455. http://dx.doi.org/10.1016/0023-9690(90)90025-J

Baloch, R. D., \& Porter, R. H. (1986). Olfactory preferences resulting from mere exposure in human neonates. Infant Behavior and Development, 9(4), 395-401. http://dx.doi.org/10.1016/0163-6383(86)90013-5

Bartoshuk, L. M., \& Beauchamp, G. K. (1994). Chemical senses. Annual Review of Psychology, 45(1), 419-449. http://dx.doi.org/10.1146/annurev.ps.45.020194.002223

Batsell, W. R., Brown, A. S., Ansfield, M. E., \& Paschall, G. Y. (2002). "You will eat all of that!”: a retrospective analysis of forced consumption episodes. Appetite, 38(3), 211-219. http://dx.doi.org/10.1006/appe.2001.0482

Baxter, S. D., \& Thompson, W. O. (2002). Fourth-grade children's consumption of fruit and vegetable items available as part of school lunches is closely related to preferences. Journal of Nutrition Education and Behavior, 34(3), 166-171. http://dx.doi.org/10.1016/S1499-4046(06)60086-9

Beauchamp, G. K., \& Mennella, J. A. (1998). Sensible phasen in der Entwicklung von Geschmacksempfindungen und-vorlieben bei Menschen. Annales Nestlé, 56, 22-34.

Beauchamp, G. K., \& Mennella, J. A. (2009). Early flavor learning and its impact on later feeding behavior. Journal of Pediatric Gastroenterology and Nutrition, 48(1S), S25-S30. http://dx.doi.org/10.1097/MPG.0b013e31819774a5

Bernstein, I. L. (1978). Learned taste aversions in children receiving chemotherapy. Science, 200(4347), 1302-1303. http://dx.doi.org/10.1126/science.663613

Bernstein, I. L., Webster, M. M., \& Bernstein, I. D. (1982). Food aversions in children receiving chemotherapy for cancer. Cancer, 50(12), 2961-2963. http://dx.doi.org/10.1002/1097-0142(19821215)50:12<2961::AID-CNCR2820501243>3.0.CO;2-L

Birch, L. L. (1992). Children's preferences for high-fat foods. Nutrition Reviews, 50(9), 249-255. http://dx.doi.org/10.1111/j.1753-4887.1992.tb01341.x

Birch, L. L. (1999). Development of food preferences. Annual Review of Nutrition, 19(1), 41-62. http://dx.doi.org/10.1146/annurev.nutr.19.1.41

Birch, L. L., \& Davison, K. K. (2001). Family environmental factors influencing the developing behavioral controls of food intake and childhood overweight. Pediatrics Clinic of North America, 48(4), 893-907. http://dx.doi.org/10.1016/S0031-3955(05)70347-3

Birch, L. L., \& Deysher, M. (1985). Conditioned and unconditioned caloric compensation: evidence for self regulation of food intake by young children. Learning and Motivation, 16(3), 341-355. http://dx.doi.org/10.1016/0023-9690(85)90020-7

Birch, L. L., \& Deysher, M. (1986). Caloric compensation and sensory specific satiety: evidence for self-regulation of food intake by young children. Appetite, 7(4), 323-331. http://dx.doi.org/10.1016/S0195-6663(86)80001-0

Birch, L. L., Gunder, L., \& Grimm-Thomas, K. (1998). Infants's consumption of a new food enhances acceptance of similar foods. Appetite, 30(3), 283-295. http://dx.doi.org/10.1006/appe.1997.0146

Birch, L. L., \& Marlin, D. W. (1982). I don't like it; I never tried it. Effects of exposure on two-year-old children's food preferences. Appetite, 3(4), 353-360. http://dx.doi.org/10.1016/S0195-6663(82)80053-6

Birch, L. L., Marlin, D. W., \& Rotter, J. (1984). Eating as the "means" activity in a contingency: effects on young children's food preference. Child Development, 55(2), 431-439. http://dx.doi.org/10.2307/1129954

Birch, L. L., McPhee, L., Steinberg, L., \& Sullivan, S. (1990). Conditioned flavor preferences in young children. Physiology and Behavior, 47(3), 501-505. http://dx.doi.org/10.1016/0031-9384(90)90116-L 
Briefel, R. R., Crepinsek, M. K., Canili, Ch., Wilson, A., \& Gleason, P. M. (2009). School food environments and practices affect dietary behaviors of US public school children. Journal of the American Dietetic Association, 109(S2), S91-S107. http://dx.doi.org/10.1016/j.jada.2008.10.059

Brown, K. A., Ogden, J., Vögele, C., \& Gibson, E. L. (2008). The role of parental control practices in explaining children's diet and BMI. Appetite, 50(2-3), 252-259. http://dx.doi.org/10.1016/j.appet.2007.07.010

Brown, R., \& Ogden, J. (2004). Children's eating attitudes and behavior: a study of the modeling and control theories of parental influence. Health Education Research, 19(3), 261-271. http://dx.doi.org/10.1093/her/cyg040

Bruer, J. T. (2001). Critical thinking about critical periods. Baltimore, ML: Paul H. Brooks Publishing.

Brug, J., Tak, N. I., Te Velde, S. J., Bere, E., \& de Bourdeaudhuij, I. (2008). Taste preferences, liking and other factors related to fruit and vegetable intakes among schoolchildren: results from observational studies. The British Journal of Nutrition, 99(1S), S7-S14. http://dx.doi.org/10.1017/S0007114508892458

Burguess-Champoux, T., Marquart, L., Vickers, Z., \& Reicks, M. (2006). Perceptions of children, parents, and teachers regarding whole-grain foods, and implications for a school-based intervention. Journal of Nutrition and Behavior, 38(4), 230-237. http://dx.doi.org/10.1016/j.jneb.2006.04.147

Capaldi, E. D., \& Privitera, G. J. (2008). Decreasing dislike for sour and bitter in children and adults. Appetite, 50(1), 139-145. http://dx.doi.org/10.1016/j.appet.2007.06.008

Chatoor, I., \& Ganiban, J. (2003). Food refusal by infants and young children: diagnosis and treatment. Cognitive and Behavioral Practice, 10(2), 138-146. http://dx.doi.org/10.1016/S1077-7229(03)80022-6

Cooke, L. (2007). The importance of exposure for healthy eating in childhood: a review. Journal of Human Nutrition and Dietetics, 20(4), 294-301. http://dx.doi.org/10.1111/j.1365-277X.2007.00804.x

Crystal, S. R., \& Bernstein, I. L. (1995). Morning sickness: impact on offspring salt preference. Appetite, 25(3), 231-240. http://dx.doi.org/10.1006/appe.1995.0058

Crystal, S. R., \& Bernstein, I. L. (1998). Infant salt preference and mother's morning sickness. Appetite, 30(3), 297-307. http://dx.doi.org/10.1006/appe.1997.0144

De Snoo, K. (1937). Das trinkende Kind im uterus. Monatsschrift für Geburtshilfe und Gynäkologie, 105(2-3), 88-97.

Delaunayl-El Allam, M., Marlier, L., \& Schaal, B. (2006). Learning at the breast: preference formation for an artificial scent and its attraction against the odor of maternal milk. Infant Behavior and Development, 29(3), 308-321. http://dx.doi.org/10.1016/j.infbeh.2005.12.008

Engström, R., \& Carlsson-Kanyama, A. (2004). Food losses in food service institutions. Examples from Sweden. Food Policy, 29(3), 203-213. http://dx.doi.org/10.1016/j.foodpol.2004.03.004

Faas, A. E., Spoltón, E. D., Moya, P. R., \& Molina, J. C. (2000). Differential responsiveness to alcohol odor in human neonates effects of maternal consumption during gestation. Alcohol, 22(1), 7-17. http://dx.doi.org/10.1016/S0741-8329(00)00103-8

Fisher, J. O., \& Birch, L. L. (1999). Restricting access to palatable foods affects children's behavioral response, food selection, and intake. American Journal of Clinical Nutrition, 69(6), 1264-72.

Fisher, J. O., Mitchell, D. C., Smiciklas-Wright, H., \& Birch, L. L. (2002). Parental influences on young girls' fruit and vegetable, micronutrient, and fat intakes. Journal of the American Dietetic Association, 102(1), 58-64. http://dx.doi.org/10.1016/S0002-8223(02)90017-9

Forestell, C. A., \& Mennella, J. A. (2005). Children's hedonic judgments of cigarette smoke odor: effects of parental smoking and maternal mood. Psychology of addictive behaviors: Journal of the Society of Psychologists in Addictive Behaviors, 19(4), 423-432. http://dx.doi.org/10.1037/0893-164X.19.4.423

Forestell, C. A., \& Mennella, J. A. (2007). Early determinants of fruit and vegetable acceptance. Pediatrics, 120(6), 1247-1254. http://dx.doi.org/10.1542/peds.2007-0858

Galloway, A. T., Fiorito, L. M., Francis, L. A., \& Birch, L. L. (2006). 'Finish your soup': counterproductive effects of pressuring children to eat on intake and affect. Appetite, 46(3), 318-323. http://dx.doi.org/10.1016/j.appet.2006.01.019

Gerrish, C. J., \& Mennella, J. A. (2001). Flavor variety enhances food acceptance in formula-feed infants. American Journal of Clinical Nutrition, 73(6), 1080-1085. 
Gibson, E. L., \& Brunstrom, J. M. (2007) Appetite and body weight: integrative systems and the development of anti-obesity drugs. London: Academic Press, Elsevier. http://dx.doi.org/10.1016/B978-012370633-1/50011-6

Gibson, E. L., \& Wardle, J. (2003). Energy density predicts preferences for fruit and vegetables in 4-year-old children. Appetite, 41(1), 97-98. http://dx.doi.org/10.1016/S0195-6663(03)00077-1

Goodman, L. S., \& Gilman, A. (1975). The pharmaceutical basis of therapeutics. New York: Macmillan Publishing.

Haller, R., Rummel, C., Henneberg, S., Pollmer, U., \& Köster, E. P. (1999). The influence of early experience with vanillin on food preference later in life. Chemical Senses, 24(4), 465-467. http://dx.doi.org/10.1093/chemse/24.4.465

Havermans, R. C. (2010). Bioactive foods in promoting health: fruits and vegetables. San Diego, Ca: Academic Press.

Havermans, R. C., \& Jansen, A. (2007). Increasing children's liking of vegetables through flavour-flavour learning. Appetite, 48(2), 259-262. http://dx.doi.org/10.1016/j.appet.2006.08.063

Heim, S., Stang, J., \& Ireland, M. (2009). A garden pilot project enhances fruit and vegetable consumption among children. Journal of the American Dietetic Association, 109(7), 1220-1226. http://dx.doi.org/10.1016/j.jada.2009.04.009

Hendy, H. M., Williams, K. E., \& Camise, T. S. (2005). "Kids choice” school lunch program increases children's fruit and vegetable acceptance. Appetite, 45(3), 250-263. http://dx.doi.org/10.1016/j.appet.2005.07.006

Hensch, T. K. (2004). Critical period regulation. Annual Review of Neuroscience, 27, 549-579. http://dx.doi.org/10.1146/annurev.neuro.27.070203.144327

Hood, M. Y., Moore, L. L., Sundarajan-Ramamurti, A., Singer, M., Cupples, L. A., \& Ellison, R. C. (2000). Parental eating attitudes and the development of obesity in children. The Framingham children's study. International Journal of Obesity, 24(10), 1319-1325. http://dx.doi.org/10.1038/sj.ijo.0801396

Johnson, M. H. (2005) Sensitive periods in functional brain development: problems and prospects. Developmental Psychobiology, 46(3), 337-344. http://dx.doi.org/10.1002/dev.20057

Johnson, S. L., McPhee, L., \& Birch, L. L. (1991). Conditioned preferences: young children prefer flavors associated with high dietary fat. Physiology and Behavior, 50(6), 1245-1251. http://dx.doi.org/10.1016/0031-9384(91)90590-K

Kern, D. L., McPhee, L., Fisher, J., Johnson, S., \& Birch, L. L. (1993). The postingestive consequences of fat condition preferences for flavors associated with high dietary fat. Physiology and Behavior, 54(1), 71-76. http://dx.doi.org/10.1016/0031-9384(93)90045-H

Knai, C., Pomerleau, J., Lock, K., \& McKee, M. (2006). Getting children to eat more fruit and vegetables: a systematic review. Preventive Medicine, 42(2), 85-95. http://dx.doi.org/10.1016/j.ypmed.2005.11.012

Knudsen, E. I. (2004). Sensitive periods in the development of the brain and behavior. Journal of Cognitive Neuroscience, 16(8), 1412-1425. http://dx.doi.org/10.1162/0898929042304796

Kringelbach, M. L. (2007). Appetite and body weight. Integrative systems and the development of anti-obesity drugs. Burlington, Ma: Academic Press.

Liem, D. G., \& De Graaf, C. (2004). Sweet and sour preferences in young children and adults: role of repeated exposure. Physiology and Behavior, 83(3), 421-429. http://dx.doi.org/10.1016/j.physbeh.2004.08.028

Liem, D. G., \& Mennella, J. A. (2002). Sweet and sour preferences during childhood: role of early experiences. Developmental Psychobiology, 41(4), 388-395. http://dx.doi.org/10.1002/dev.10067

Liley, A. W. (1972). Pathophysiology of gestation. New York: Academic Press.

Lytle, L. A. (2009). Measuring the food environment. American Journal of Preventive Medicine, 36(4S), S134-S144. http://dx.doi.org/10.1016/j.amepre.2009.01.018

Macfarlane, A. (1975). Olfaction in the development of social preferences in the human neonate. Ciba Foundation Symposium, 33, 103-117.

Maier, A., Chabanet, C., Schaal, B., Issanchou, S., \& Leathwood, P. (2007). Effects of repeated exposure on aceptance of initially disliked vegetables in 7-month old infants. Food Quality and Preference, 18(8), 
1023-1032. http://dx.doi.org/10.1016/j.foodqual.2007.04.005

Maier, A. S., Chabanet, C., Schaal, B., Leathwood, P. D., \& Issanchou, S. N. (2008). Breastfeeding and experience with variety early in weaning increase infants' acceptance of new foods for up two months. Clinical Nutrition, 27(6), 849-857. http://dx.doi.org/10.1016/j.clnu.2008.08.002

Marlier, L., Schaal, B., \& Soussignan, R. (1998). Bottle-fed neonates prefer an odor experienced in utero to an odor experienced postnatally in the feeding context. Developmental Psychobiology, 33(2), 133-145. http://dx.doi.org/10.1002/(SICI)1098-2302(199809)33:2<133::AID-DEV4>3.0.CO;2-K

McDermott, B., Forbes, D., Harris, Ch., McCormack, J., \& Gibbon, P. (2006). Non-eating disorders psychopathology in children and adolescents with eating disorders: implications for malnutrition and symptom severity. Journal of Psychosomatic Research, 60(3), 257-261. http://dx.doi.org/10.1016/j.jpsychores.2005.08.004

Mennella, J. A. (2001). Regulation of milk intake after exposure to alcohol in mothers' milk. Alcoholism, Clinical and Experimental Research, 25(4), 590-593. http://dx.doi.org/10.1111/j.1530-0277.2001.tb02254.x

Mennella, J. A., \& Beauchamp, G. K. (1991a). Maternal diet alters the sensory qualities on human milk and the nursling's behavior. Pediatrics, 88(4), 737-744.

Mennella, J. A., \& Beauchamp, G. K. (1991b). The transfer of alcohol to human milk: effects on flavor and the infant's behavior. The New England Journal of Medicine, 325(14), 981-985. http://dx.doi.org/10.1056/NEJM199110033251401

Mennella, J. A., \& Beauchamp, G. K. (1994). The infant's response to flavored milk. Infant Behavior and Development, 17, 819 .

Mennella, J. A., \& Beauchamp, G. K. (1996). The human infants' response to vanilla flavours in mother's milk

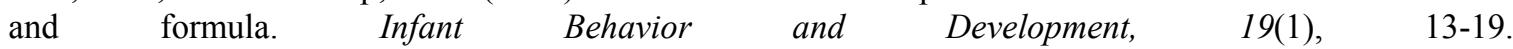
http://dx.doi.org/10.1016/S0163-6383(96)90040-5

Mennella, J. A., \& Beauchamp, G. K. (1997a). Smelling and tasting. Handbook of perception and cognition. San Diego, Ca: Academic Press.

Mennella, J. A., \& Beauchamp, G. K. (1997b). Mothers' milk enhances the acceptance of cereal during weaning. Pediatric Research, 41(2), 188-192. http://dx.doi.org/10.1203/00006450-199702000-00006

Mennella, J. A., \& Beauchamp, G. K. (1998a). Early flavor experiences: research update. Nutrition Reviews, 56(7), 205-211. http://dx.doi.org/10.1111/j.1753-4887.1998.tb01749.x

Mennella, J. A., \& Beauchamp, G. K. (1998b). Infants' exploration of scented toys: effects of prior experiences. Chemical Senses, 23(1), 11-17. http://dx.doi.org/10.1093/chemse/23.1.11

Mennella, J. A., \& Beauchamp, G. K. (1999). Experience with a flavor in mother's milk modifies the infant's acceptance of flavored cereal. Developmental Psychobiology, 35(3), 197-203. http://dx.doi.org/10.1002/(SICI)1098-2302(199911)35:3<197::AID-DEV4>3.0.CO;2-J

Menella, J. A., \& Beauchamp, G. K. (2002). Flavor experiences during formula feeding are related to preferences during childhood. Early Human Development, 68, 71-82. http://dx.doi.org/10.1016/S0378-3782(02)00008-7

Mennella, J. A., \& Beauchamp, G. K. (2005). Understanding the origin of flavor preferences. Chemical Senses, 30(1), 242-243. http://dx.doi.org/10.1093/chemse/bjh204

Mennella, J. A., \& Beaucahmp, G. K. (2009). Early flavor learning and its impact on later feeding behavior. Journal of Pediatric Gastroenterology and Nutrition, 48(1S), S25-S30. http://dx.doi.org/10.1097/MPG.0b013e31819774a5

Mennella, J. A., \& Beauchamp, G. K. (2010). Obesity Prevention. The role of brain and society on individual behavior. San Diego, Ca: Academic Press.

Mennella, J. A., Coren, P., Jagnow, C. P., \& Beauchamp, G. K. (2001). Prenatal and postnatal flavor learning by human infants. Pediatrics, 107(6), e88. http://dx.doi.org/10.1542/peds.107.6.e88

Mennella, J. A., Forestell, C. A., Morgan, L. K., \& Beauchamp, G. K. (2009). Early milk feeding influences taste acceptance and liking during infancy. American Journal of Clinical Nutrition, 90(3S), S780-S788. http://dx.doi.org/10.3945/ajen.2009.27462O

Mennella, J. A., \& García, P. L. (2000). Children's hedonic response to the smell of alcohol: effects of parental drinking habits. Alcoholism: Critical and Experimental Research, 24(8), 1167-1171. 
Mennella, J. A., Griffin, C. E., \& Beauchamp, G. K. (2004). Flavor programming during infancy. Pediatrics, 113(4), 840-845. http://dx.doi.org/10.1542/peds.113.4.840

Mennella, J. A., Johnson, A., \& Beauchamp, G. K. (1995). Garlic ingestion by pregnant women alters the odor of amniotic fluid. Chemical Senses, 20(2), 207-209. http://dx.doi.org/10.1093/chemse/20.2.207

Mennella, J. A., Kennedy, J. M., \& Beauchamp, G. K. (2006). Vegetable acceptance by infants: effects of formula flavors. Early Human Development, 82(7), 463-468. http://dx.doi.org/10.1016/j.earlhumdev.2005.12.001

Mennella, J. A., Lukasewycz, L. D., Castor, S. M., \& Beauchamp, G. K. (2011). The timing and duration of a sensitive period in human flavor learning: a randomized trial. American Journal of Clinical Nutrition, 93(5), 1019-1024. http://dx.doi.org/10.3945/ajcn.110.003541

Mennella, J. A., Nicklaus, S., Jagolino, A. L., \& Yourshaw, L. M. (2008). Variety is the spice of life: strategies for promoting fruit and vegetable acceptance during infancy. Physiology and Behavior, 94(1), 29-38. http://dx.doi.org/10.1016/j.physbeh.2007.11.014

Mennella, J. A., Pepino, M. Y., \& Reed, D. R. (2005). Genetic and environmental determinants of bitter perception and sweet preferences. Pediatrics, 115(2), 216-222. http://dx.doi.org/10.1542/peds.2004-1582

Mennella, J. A., Turnbull, B., Ziegler, P. J., \& Martínez, H. (2005). Infant feeding practices and early flavor experiences in Mexican infants: an intra-cultural study. Journal of the American Dietetic Association, 105(6), 908-915. http://dx.doi.org/10.1016/j.jada.2005.03.008

Mizuno, K., \& Ueda, A. (2004). Antenatal olfactory learning influences infant feeding. Early Human Development, 76(2), 83-90. http://dx.doi.org/10.1016/j.earlhumdev.2003.10.003

Mobini, S., Chambers, L. C., \& Yeomans, M. R. (2007). Effects of hunger stae on flavour pleasantness conditoning at home: flavour-nutrient learning vs. flavour-flavour learning. Appetite, 48(1), 20-28. http://dx.doi.org/10.1016/j.appet.2006.05.017

Mojet, J., Christ-Hazelhof, E., \& Heidema, J. (2001). Taste perception with age: generic or specific losses in threshold sensitivity to the five basic tastes? Chemical Senses, 26(7), 845-860. http://dx.doi.org/10.1093/chemse/26.7.845

Mojet, J., Christ-Hazelhof, E., \& Heidema, J. (2005). Taste perception with age: pleasantness and its relationships with threshold sensitivity and supra-threshold intensity of five taste qualities. Food Quality and Preference, 16(5), 413-423. http://dx.doi.org/10.1016/j.foodqual.2004.08.001

Moore, S. N., Murphy, S., Tapper, K., \& Moore, L. (2010). From policy to plate: barriers to implementing healthy eating policies in primary schools in Wales. Health Policy, 94(3), 239-245. http://dx.doi.org/10.1016/j.healthpol.2009.10.001

Morris, J. L., Neustadter, A., \& Zidenberg-Cherr, S. (2001). First-grade gardeners more likely to taste vegetables. California Agriculture, 55(1), 43-46. http://dx.doi.org/10.3733/ca.v055n01p43

Morris, J. L., \& Zidenberg-Cherr, S. (2002). Garden-enhanced nutrition curriculum improves fourth-grade school children's knowledge of nutrition and preferences for some vegetables. Journal of the American Association of Nutrition, 102(1), 91-93.

Nicklaus, S., Boggio, V., Chabanet, C., \& Issanchou, S. (2004). A prospective study of food preferences in $\begin{array}{llll}\text { childhood. Food } & \text { Quality and Preference, } & \text { 15(7-8), }\end{array}$ http://dx.doi.org/10.1016/j.foodqual.2004.02.010

Nicklaus, S., Boggio, V., Chabanet, C., \& Issanchou, S. (2005). A prospective study of food seeking in childhood, adolescence and early adult life. Appetite, 44(3), 289-297. http://dx.doi.org/10.1016/j.appet.2005.01.006

Pliner, P. (1982). The effects of mere exposure on liking for edible substances. Appetite, 3(3), 283-290. http://dx.doi.org/10.1016/S0195-6663(82)80026-3

Pynoos, R. S., Steinberg, A. M., \& Piacenini, J. C. (1999). A developmental psychopathology model of childhood traumatic stress and intersection with anxiety disorders. Biological Psychiatry, 46(11), 1542-1554. http://dx.doi.org/10.1016/S0006-3223(99)00262-0

Rasmussen, M., Krølner, R., Klepp, K. I., Lytle, L., Brug, J., Bere, E., \& Due, P. (2006). Determinants of fruit and vegetable consumption among children and adolescents: a review of the literature. Part 1: quantitative studies. The International Journal of Behavioral Nutrition and Physical Activity, 3(22), 1-19. http://dx.doi.org/10.1186/1479-5868-3-22 
Reimer, K., Smith, Ch., Reicks, M., Henry, H., Thomas, R., \& Atwell, J. (2003). Child-feeding strategies of African American women according to stage of change for fruit and vegetable consumption. Public Health Nutrition, 7(4), 505-512.

Reverdy, C., Schlich, P., Köster, E. P., Ginon, E., \& Lange, C. (2010). Effect of sensory education on food preferences in children. Food Quality and Preference, 21(7), 794-804. http://dx.doi.org/10.1016/j.foodqual.2010.03.008

Rohlfs Domínguez, P. (2011). The study of postnatal and later development of the taste and olfactory systems using the human brain mapping approach: An update. Brain Research Bulletin, 84(2), 118-124. http://dx.doi.org/10.1016/j.brainresbull.2010.12.010

Rolls, B. J., Rowe, E. S., \& Rolls, E. T. (1982). How sensory properties of foods affect human feeding behavior. Physiology and Behavior, 29(3), 409-417. http://dx.doi.org/10.1016/0031-9384(82)90259-1

Romero, N. D., Epstein, L. H., \& Salvy, S. J. (2009). Peer modeling influences girls' snack intake. Journal of the American Dietetic Association, 109(1), 133-136. http://dx.doi.org/10.1016/j.jada.2008.10.005

Rozin, P. (1979). Preference and chemoreception. Oxford: Oxford University Press.

Rozin, P., \& Fallon, A. E. (1987). A perspective on disgust. Psychological Review, 94(1), 23-41. http://dx.doi.org/10.1037/0033-295X.94.1.23

Rozin, P., \& Vollmecke, A. (1986). Food likes and dislikes. Annual Review of Nutrition, 6, 433-456. http://dx.doi.org/10.1146/annurev.nu.06.070186.002245

Russel, M. J. (1976). Human olfactory communication. Nature, 260, 520-522. http://dx.doi.org/10.1038/260520a0

Savage, J. S., Fisher, J. O., \& Birch, L. L. (2007). Parental influence on eating behavior: Conception to adolescence. Journal of Law, Medicine and Ethics, 35(1), 22-34. http://dx.doi.org/10.1111/j.1748-720X.2007.00111.x

Scaglioni, S., Salvioni, M., \& Galimberti. (2008). Influence of parental attitudes in the development of children $\begin{array}{lllll}\text { eating behavior. British Journal of Nutrition, 99(1S), S22-S25. } & \end{array}$ http://dx.doi.org/10.1017/S0007114508892471

Schaal, B. (1999). Le développement de la sensibilité olfactive: de la période à la puberté. Neuilly Sur Seine: Irvinn Editions.

Schaal, B. (2005). Prenatal development of postnatal functions. Westport CT: Praeger Publishers.

Schaal, B., \& Marlier, L. (1998). Olfactory function in the human fetus: evidence from selective neonatal responsiveness to the odor of amniotic fluid. Behavioral Neuroscience, 112(6), 1438-1449. http://dx.doi.org/10.1037/0735-7044.112.6.1438

Schaal, B., Marlier, L., \& Soussignan, R. (2000). Human fetuses learn odours from their pregnant mother's diet. Chemical Senses, 25(6), 729-737. http://dx.doi.org/10.1093/chemse/25.6.729

Sepp, H., Abrahamsson, L., Junberger, M. L., \& Risvik, E. (2002). The contribution of food groups to the nutrient intake and food pattern among pre-school children. Food Quality and Preference, 13(2), 107-116. http://dx.doi.org/10.1016/S0950-3293(01)00071-4

Skinner, J. D., Bounds, W., Carruth, B. R., Morris, M., \& Ziegler, P. (2004). Predictors of children's body mass index: a longitudinal study of diet and growth in children aged 2-8 y. International Journal of Obesity and Related Metabolic Disorders, 28(4), 476-482. http://dx.doi.org/10.1038/sj.ijo.0802405

Skinner, J. D., Carruth, B. R., Bounds, W., \& Ziegler, P. J. (2002). Children's food preferences: a longitudinal analysis. Journal of the American Dietetic Associaiton, 102(11), 1638-1647. http://dx.doi.org/10.1016/S0002-8223(02)90349-4

Skinner, J. D., Carruth, B. R., Bounds, W., Ziegler, P., \& Reidy, K. (2002). Do food-related experiences in the first 2 years of life predict dietary variety in school-aged children? Journal of Nutrition Education and Behavior, 34(6), 310-315. http://dx.doi.org/10.1016/S1499-4046(06)60113-9

Small, D. M., \& Prescott, J. (2005). Odor/taste integration and the perception of flavor. Experimental Brain Research, 166(3-4), 345-357. http://dx.doi.org/10.1007/s00221-005-2376-9

Sosa, M., \& Hough, G. (2006). Sensory acceptability of menus and sweet snacks among children and adults from low- and medium-income households in Argentina. Food Quality and Preference, 17(7-8), 590-597. 
http://dx.doi.org/10.1016/j.foodqual.2006.04.001

Spolidoro, M., Sale, A., Berardi, N., \& Maffei, L. (2009). Plasticity in the adult brain: lessons from the visual system. Experimental Brain research, 192(3), 335-341. http://dx.doi.org/10.1007/s00221-008-1509-3

Sullivan, S. A., \& Birch, L. L. (1990). Pass the sugar, pass the salt: experience dictates preference. Developmental Psychology, 26(4), 546-551. http://dx.doi.org/10.1037/0012-1649.26.4.546

Sullivan, S. A., \& Birch, L. L. (1994). Infant dietary experience and acceptance of solid foods. Pediatrics, 93(2), 271-277.

Sullivan, S. A., \& Toubas, P. (1998). Clinical usefulnes of maternal odor in newborns: soothing and feeding preparatory responses. Biology of the Neonate, 74(6), 402-408. http://dx.doi.org/10.1159/000014061

Timini, S., Douglas, J., \& Tsiftsopoulou, K. (1997). Selective eaters: a retrospective case note study. Child, Care, Health and Development, 23(3), 265-278. http://dx.doi.org/10.1111/j.1365-2214.1997.tb00968.x

Torrance, E. P. (1958). Sensitization versus adaptation in preparation for emergencies: prior experience with an emergency ration and its acceptability in a simulated survival situation. Journal of Applied Psychology, 42(1), 63-67. http://dx.doi.org/10.1037/h0044389

Van Eys, J. (1979). Malnutrition in children with cancer: incidence and consequence. Cancer, 43(5), 2030-2035. http://dx.doi.org/10.1002/1097-0142(197905)43:5+<2030::AID-CNCR2820430711>3.0.CO;2-S

Varendi, H., Christensson, K., Porter, R. H., \& Winberg, J. (1998). Soothing effect of amniotic fluid smell in newborn infants. Early Human Development, 51(1), 47-55. http://dx.doi.org/10.1016/S0378-3782(97)00082-0

Varendi, H., Porter, R. H., \& Winberg, J. (1994). Does the newborn baby find the nipple by smell? The Lancet, 344(8928), 989-990. http://dx.doi.org/10.1016/S0140-6736(94)91645-4

Varendi, H., \& Porter, R. H. (2001). Breast odour as the only maternal stimulus elicits crawling towards the odour source. Acta Paediatrica, 90(4), 372-375. http://dx.doi.org/10.1080/080352501750126131

Varendi, H., Porter, R. H., \& Winberg, J. (2002). The effect of labor on olfactory exposure learning within the first postnatal hour. Behavioral Neuroscience, 116(2), 206-211. http://dx.doi.org/10.1037/0735-7044.116.2.206

Wang, M. C., Rauzon, S., Studer, N., Martin, A. C., Craig, L., Merlo, C., ... Crawford, P. (2010). Exposure to a comprehensive school intervention increases vegetable consumption. Journal of Adolescent Health, 47(1), 74-82. http://dx.doi.org/10.1016/j.jadohealth.2009.12.014

Wardle, J. (1995). Parental influences on children's diets. Proceedings of the Nutrition Society, 54, 747-758. http://dx.doi.org/10.1079/PNS19950074

Wardle, J., Carnell, S., \& Cooke, L. (2005). Parental control over feeding and children's fruit and vegetable intake: how are they related? The American Dietetic Association, 105(2), 227-232. http://dx.doi.org/10.1016/j.jada.2004.11.006

Wardle, J., Herrera, M. L., Cooke, L. J., \& Gibson, E. L. (2003). Modifying children's food preferences: the effects of exposure and reward on acceptance of an unfamiliar food. European Journal of Clinical Nutrition, 57(2), 341-348. http://dx.doi.org/10.1038/sj.ejcn.1601541

Wardle, J., Sanderson, S., Gibson, E. L., \& Rapoport, L. (2001). Factor-analytic structure of food preferences in four-year-old in the UK. Appetite, 37(3), 217-223. http://dx.doi.org/10.1006/appe.2001.0423

Warren, E., Parry, O., Lynch, R., \& Murphy, S. (2008). If I don't like then I can choose what I want: Welsh school children's accounts of preference for and control over food choice. Health Promotion International, 23(2), 144-151. http://dx.doi.org/10.1093/heapro/dam045

Weker, H. (2006). Simple obesity in children. A study on the role of nutritional factors. Medycyna Wieku Rozwojowego, 10(1), 3-191.

WHO. (2009). Promoting fruit and vegetable consumption arround the world. World Health Organisation. Retrieved July, 17, 2009, from http://www.who.int/dietphysicalactivity/fruit/en/index.html

Williams, K. E., Paul, C., Pizzo, B., \& Riegel, K. (2008). Practice does make perfect: a longitudinal look at repeated taste exposure. Appetite, 51(3), 739-742. http://dx.doi.org/10.1016/j.appet.2008.05.063 
Wind, M., De Bourdeaudhuij, I., te Velde, S. J., Sandvik, C., Klepp, K. I., Due, P., \& Brug, J. (2006). Correlates of fruit and vegetable consumption among 11-years-old Belgian-Flemish and Dutch schoolchildren. Journal of Nutrition, Education and Behavior, 38(4), 211-221. http://dx.doi.org/10.1016/j.jneb.2006.02.011

Zeinstra, G. G., Koelen, M. A., Kok, F. J., \& De Graaf, C. (2009). Children's hard-wired aversion to pure vegetable tastes. A 'failed' flavour-nutrient learning study. Appetite, 52(2), 528-30. http://dx.doi.org/10.1016/j.appet.2008.11.006

Zellner, D. A., Rozin, P., Aron, M., \& Kulish, C. (1983). Conditioned enhancement of human's liking for flavor by pairing with sweetness. Learning and Motivation, 14(3), 338-350. http://dx.doi.org/10.1016/0023-9690(83)90021-8

\section{Copyrights}

Copyright for this article is retained by the author(s), with first publication rights granted to the journal.

This is an open-access article distributed under the terms and conditions of the Creative Commons Attribution license (http://creativecommons.org/licenses/by/3.0/). 